ENTREVISTA

\title{
PROGRAMA INFORMÁTICA E EDUCAÇÃO
}

O Programa Informática e Educação (PIE), desenvolvido pelo Senac em São Paulo entre 1986 e 1996, marcou época, reconhecido pela excelente qualidade, e tem conquistas presentes até hoje. Em meados de 1980, o Senac-SP estava redesenhando seus caminhos e questionando a si mesmo sobre como seria a educação do futuro. Nesse contexto, a Gerência de Educação Profissional foi quem assumiu o projeto. Muitas pessoas contribuíram para a construção do PIE, aliás, essa é uma das características que marcaram esse grupo: o espírito de colaboração. Por isso esta entrevista coletiva, revelando um pouco de nossa dinâmica. Vamos então conhecer os personagens dessa história inovadora.

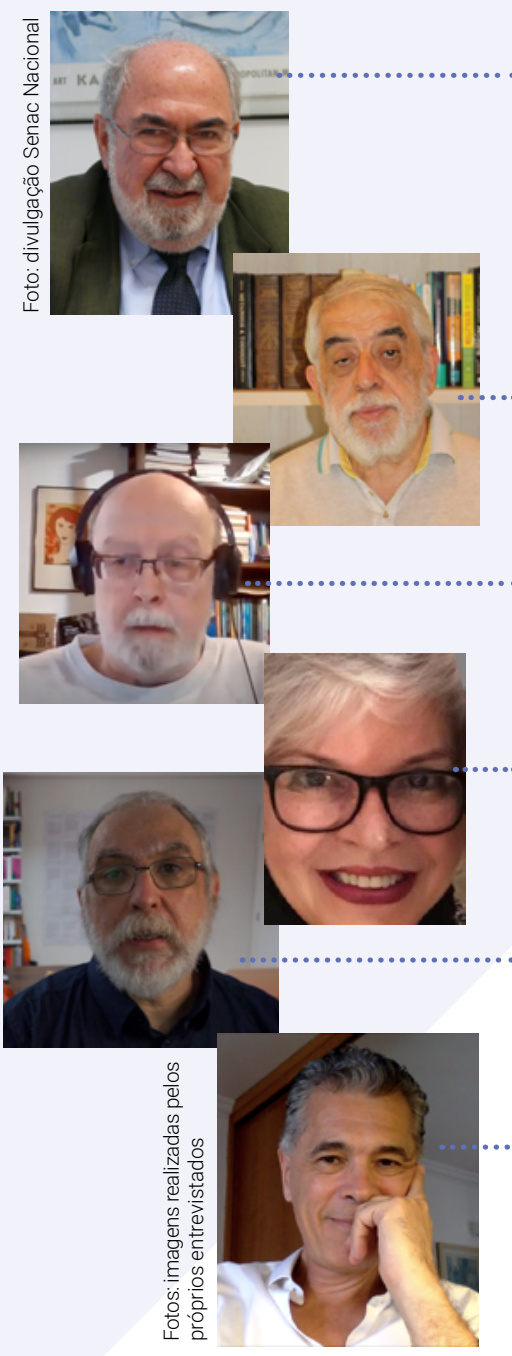

\section{Francisco Aparecido Cordão}

Educador, sociólogo e filósofo. Especialista em Educação Profissional. É membro do Conselho de Educação do Município e do Estado de São Paulo e da Câmara de Educação Básica do Conselho Nacional de Educação (CNE). Atuou durante mais de 30 anos no Senac em São Paulo. É Titular da Cadeira n. 28 da Academia Paulista de Educação, bem como Oficial e Comendador da Ordem Nacional do Mérito Educativo Nacional. Atualmente, preside a Peabiru Educacional e participa do Conselho Consultivo da Cátedra de Educação Básica do Instituto de Estudos Avançados (IEA), da Universidade de São Paulo (USP), em parceria com o Itaú Social. E-mail: facordao@uol.com.br

\section{Jarbas Novelino Barato}

Idealizador do PIE. Posteriormente, atuou em projetos de tecnologia educacional na Escola do Futuro, da USP, Fundação Telefônica, Fundação Padre Anchieta, Webquest.cat da Catalunha e Secretarias de Educação de São Paulo e Paraná. E-mail: jarbas.barato@gmail.com

\section{Carlos Seabra}

Editor e produtor de conteúdos culturais e educacionais de multimídia e internet, consultor e coordenador de projetos de tecnologia educacional e redes sociais, autor de livros, criador de jogos e softwares educacionais e culturais. E-mail: carlos@seabra.com

\section{Rosemary Soffner}

Professora, palestrante e consultora para diferentes níveis de ensino e setores, assim como para editoras no desenvolvimento de objetos e projetos de tecnologia educacional.

E-mail: rosemary.soffner@gmail.com

\section{Luciano Ramalho}

Foi programador no PIE. É instrutor de programação em cursos livres desde 1985. Autor do livro Fluent Python (O'Reilly, 2015). É consultor na ThoughtWorks, uma consultoria global de engenharia de software. E-mail: luciano@ramalho.org

\section{. Fernando Moraes Fonseca Júnior}

Profissional dedicado à educação e à formação profissional, com ênfase em tecnologias digitais, design de jogos, inovação e transformação digital, tendo ocupado posições de liderança em projetos e operações no Brasil e na América Latina, em organizações como Senac, Pontifícia Universidade Católica de São Paulo (PUC-SP), Santillana, Fundação Vanzolini, TV Cultura, FTD e Ministério da Educação (MEC). E-mail: ffonseca.jr@gmail.com 
FAC - Como e quando surgiu o Programa Informática e Educação (PIE) no Senac em São Paulo?

JNB - Formalmente, o programa surgiu a partir de um projeto que desenvolvi em 1986 e foi aprovado pela Diretoria Regional em dezembro do mesmo ano. Mas, antes disso, já existiam atividades que buscavam associar informática e educação, que eram conduzidas pela unidade especializada no ensino de informática. O Carlos Seabra, a Sônia Zeitune e o Luciano Ramalho trabalharam nesse embrião do PIE.

\section{FAC - Conte-nos um pouco do projeto que você propôs.}

JNB - Eu concluí o mestrado em Tecnologia Educacional na San Diego State University (SDSU) em 1984. De volta ao Brasil, demorei alguns meses para examinar como a informática estava ingressando em todas as atividades do Senac. No processo, ajudei a desenvolver materiais e propostas para o ensino da informática no Regional. Acompanhei a produção de um manual para ensino de programação no Sinclair (um pequeno computador que chegou a ser bem popular no Brasil) e escrevi, com uma engenheira de computação, a Terezinha Cavalheiro, o manual de Basic para o Itautec Júnior. Durante todo esse tempo eu estava pensando em como poderia propor a entrada do Senac no mundo do uso de computadores em atividades de ensino. Dei o primeiro passo nessa direção traduzindo e adaptando o Manual de Applesoft Basic para educação e treinamento. A obra original era o material produzido por Bernie Dodge, professor do Departamento de Tecnologia Educacional da Faculdade de Educação da SDSU, para a disciplina Computer Education. Além de traduzir o material do Bernie, acrescentei ao manual uma introdução sobre tecnologia educacional, e um capítulo final de autoria de Al Rogers. Com isso, passamos a ter um material que poderia ser ponto de partida para a capacitação de nossos docentes na utilização de computadores no ensino. Conto uma curiosidade sobre esse manual. Havia uma equipe de datilógrafas que cuidava da versão gráfica final do material que eu estava traduzindo. Quando o manual ficou pronto, uma das datilógrafas, Lígia Tizuko Carlos, me disse: "Este manual dispensa professor". Acho que ela não tinha razão, pois o próprio manual previa mediação do professor para apoiar a aprendizagem do aluno. Mas, por outro lado, o comentário da Lígia foi muito elogioso com relação à qualidade didática do manual. Tudo era muito claro e dava a cada aluno a possibilidade de avançar de acordo com seu próprio ritmo.

FMFJ - Eu iniciei a minha formação em programação de computadores estudando sozinho o manual que você traduziu e adaptou.

CS - Você trouxe para nós uma proposta que refletia muito o que se fazia na SDSU e no departamento de educação do condado de San Diego.

JNB - É verdade. O modo pelo qual Bernie Dodge e Al Rogers (meu professor de Computer Education) entendiam relações entre informática e educação teve grande influência na proposta que fiz para o Senac. Com Bernie aprendi que os professores precisam ser atores importantes no processo de introdução da informática no ensino. Já com Rogers aprendi que os professores, além de atores importantes, tinham que 
ter voz ativa nas decisões sobre a entrada dos computadores nas escolas. Até hoje cito uma frase que o Rogers nos disse certo dia: "Para que a informática tenha sucesso em atividades de ensino, é preciso que os professores tenham a chave do laboratório". Na época, nas escolas americanas (e depois no Brasil), a chave do laboratório, física e simbolicamente, ficava com um especialista. Os professores não tinham voz ativa no processo. Tudo era decidido pelo especialista. Não esqueci a lição do Rogers. Sempre achei que, sem a participação dos professores desde o início, não se faz o uso adequado de computadores em educação.

LR - Conhecemos o Bernie. Ele desenvolveu um seminário sobre simulações para nós. Um seminário memorável, que o colocou na galeria dos melhores professores que já vi na vida. Além disso, posteriormente, nosso amigo da SDSU se tornou um nome conhecido em todo o mundo pela criação do modelo WebQuest para uso da internet em educação. Mas quem é o Al Rogers?

JNB - O Al Rogers era, entre outras coisas, professor de Computer Education no mestrado em Tecnologia Educacional da SDSU. Era um instructor, ou seja, um professor contratado por tempo determinado para ensinar alguma disciplina que não podia ser assumida pelo professor titular. Ele lecionava matemática na rede pública. Quando os computadores chegaram à sua escola, Rogers pediu a chave para o diretor e iniciou um amplo programa de uso de computadores com ajuda de jovens hackers da cidade e de professores como Bernie Dodge. Ele criou um projeto para uso de computadores que promoveu (e ainda promove) cooperação entre escolas no mundo inteiro, o Global SchoolNet. Em 1984, época em que a internet ainda não existia, Rogers criou uma plataforma que facilitava a cooperação entre professores, a Free Educational Mail (FrEdMail). Essa iniciativa o projetou como uma das figuras mais importantes de informática e educação nos Estados Unidos nos anos 1980. Dou aqui um destaque à figura do Al Rogers porque ele não era um acadêmico, por isso deve ser muito pouco conhecido no Brasil. Era um professor de ensino médio. Não produzia papers. Produzia materiais para uso do computador em educação, sempre em colaboração com os professores ou para atender a necessidades imediatas desses. Passados mais de 30 anos, revendo o que fizemos, acho que as ideias e realizações do Al Rogers tiveram grande influência sobre a proposta que fiz para o Senac.

\section{FAC - Acho que estamos nos desviando um pouco do assunto, Jarbas. Volte mais es- pecificamente para a sua proposta em relação ao Programa Informática e Educa- ção, que é o objeto de nossa entrevista.}

JNB - A partir da minha experiência com professores no Senac, julguei que deveríamos começar pela área da Saúde. Nossos profissionais da área tinham formação bastante sólida. Além disso, havia muitos conteúdos científicos no currículo que poderiam ser objeto de softwares educacionais interessantes. Na proposta, ressaltei muito a necessidade de contar desde o início com a participação efetiva dos professores, mas, na época, o uso de computadores exigia ingresso em certos mistérios arcanos da informática. Do contrário, teríamos muitos docentes indagando o que 
fazer diante da tela negra do computador. Propus uma capacitação bastante exigente. Na prática, apresentei um programa de formação de docentes que era muito parecido com a disciplina Computer Education que Bernie e Al Rogers ensinavam na SDSU. Isso abrangia ensino do Applesoft Basic, planejamento de software educacional e informações sobre impactos da tecnologia na sociedade, o que acontecia em um dia de encontro com o professor Newton Bryan, da Universidade Estadual de Campinas (Unicamp), e o professor Jorge Froes, um dos pioneiros do uso do Logo no Brasil. Mas a peça de resistência da capacitação dos docentes era a elaboração de um produto, de um software educacional, abordando um assunto escolhido pelo professor. A capacitação se encerrava com a apresentação de todos os projetos desenvolvidos pelos professores rodando no computador. Ao elaborar a proposta inicial, eu já pensava na segunda área que seria integrada ao programa, a de idiomas. E ela começou a ser trabalhada uns dois anos após a instalação do PIE.

LR - Para mim, a capacitação de professores no âmbito do PIE tinha uma certa dimensão de "sofrimento", ou seja, os professores eram desafiados no limite máximo. Tinham que produzir um software, o que não era uma atividade banal para quem nunca tivera oportunidade de trabalhar com computadores na vida.

JNR - Acho que essa ideia de "sofrimento" precisa ser bem-entendida. No início da capacitação, os professores ficavam assustados com a exigência. "Produzir um software? Eu, professora de anatomia e fisiologia?". Mas, com o decorrer da capacitação, os docentes iam ganhando confiança e no final estavam bastante à vontade para se verem como autores de um software educacional. A exigência fazia parte do que aprendi em meu mestrado na SDSU. Qualquer que fosse a área de estudo em que ingressávamos, havia sempre a pergunta: "O que você vai produzir neste curso?" Isso abrangia, inclusive, disciplinas com grande carga teórica. Em Pesquisa Avançada em Educação, disciplina que exigia um mergulho profundo em aspectos teóricos, já no primeiro dia de aula nos perguntavam: "Que pesquisa você vai produzir neste curso?".

FMFJ - A exigência de produção de um software nos dava oportunidade de trabalhar com os professores. Assim que surgia a ideia de um software, nossa equipe e o grupo de docentes começavam a discutir com o autor ou autora se era ou não adequado propor ensino por computador com aquele conteúdo. Discutíamos, em cada caso, aspectos de planejamento de ensino, limites e possibilidades em termos de programação, tipo de software que seria produzido etc.

JNB - Essa era a principal qualidade da capacitação que a gente desenvolvia. Como diz Gardner: "A gente aprende por meio de atividades" que nos desafiam, servem de teste para nossas ideias (teorias), sinalizam buscas que precisamos fazer, dão sentido ao significado do que se está aprendendo. O pressuposto do nosso programa era o de que tecnologia é uma questão de cabeça, e não de máquina e equipamentos. Por isso não bastava comprar máquinas, sistemas e softwares. Era preciso ter, dentro do Senac, pessoas capazes de produzir softwares educacionais. Em nossa 
proposta, essas pessoas eram os professores e a equipe de especialistas do PIE. Conforme passamos a produzir softwares educacionais, colocamos o Senac no restrito grupo de instituições que dominam a tecnologia. Conto aqui um caso para ilustrar isso. Um dia, fomos convidados a falar do PIE para executivos de recursos humanos de um grupo de multinacionais com negócios no Brasil. Fernando, Seabra e eu fizemos uma apresentação ilustrada por softwares que já havíamos produzido. Nossos ouvintes ficaram impressionados. No almoço, um dos executivos me perguntou: "Vocês fazem consultoria para o Senac?" Quem perguntou não imaginava que o Senac pudesse produzir tecnologia; ele achava que a instituição seria compradora da mesma. Isso indica um entendimento do que é tecnologia na contramão daquilo que praticávamos. O perguntante achava que tecnologia fosse um produto que pode ser vendido e comprado no mercado. Nós entendíamos que tecnologia é um empreendimento que depende, sobretudo, de capacidade de fazer, de realizar.

RS - Além da produção de softwares, a capacitação de professores tinha outros resultados. Um exemplo é Anotações de Enfermagem, série de vídeos que produzimos para melhorar o ensino do conteúdo desse tipo de redação no curso Auxiliar de Enfermagem. Mais à frente, precisamos falar de tal produto.

JNB - A Rose lembra um aspecto que discutíamos muito em cada proposta feita pelos professores. Algumas delas não eram programáveis. Ou, para colocar de outra forma, o uso de computadores não seria vantajoso para melhorar o ensino e os resultados de aprendizagem. Às vezes, simplesmente deixávamos de lado o que não era programável, sempre com a concordância do autor ou autora da proposta. Como no caso do Anotações de Enfermagem, embarcávamos na aventura de produzir material em outra mídia que não o computador. Mas eu queria acrescentar aqui outra consequência da capacitação de professores. Muitos deles se encantavam com propostas didáticas presentes em determinados softwares educacionais. Uma série de softwares muito popular na época era a Decision/decisions, de Tom Snyder, modelo de simulação que engajava os alunos na solução de problemas. Na época, não fizemos algo parecido com o modelo proposto por Snyder, mas nossos professores estudavam os softwares dele durante a capacitação. E um desses professores, o Fábio, docente do curso Auxiliar de Enfermagem, não tendo oportunidade de produzir um software na direção do modelo criado por Snyder, resolveu reproduzi-lo em sala de aula. Em vez de usar o computador para simular decorrências de decisões dos alunos, dada uma situação-problema, Fábio construiu tudo no papel e atuava como se fosse um programa que avalia a decisão tomada e propõe novo problema a ser resolvido a partir dela. Isso Ihe impunha uma grande carga de controle do fluxo de informações, mas imitava muito bem o que Snyder convertia em software. Aliás, convém assinalar que o próprio Snyder, antes de conhecer computadores, fazia algo parecido com o que o Fábio fez. O trabalho de nosso docente tinha tanta qualidade que foi escolhido para ser apresentado em um congresso nacional de ensino de enfermagem. 
FAC - 0 assunto está muito interessante e merece até uma entrevista à parte. Entretanto, mais uma vez, Jarbas, é preciso voltar para a pergunta que fiz sobre a proposta inicial do PIE.

JNB - Creio que, mesmo com as voltas que demos, deve ter ficado claro qual era o objetivo central do PIE: desenvolver tecnologia. Assim, a gente fugia da ideia de que é possível transferir tecnologia. Tal ideia coloca o acento em produtos já prontos, em máquinas, em sistemas. Nosso projeto colocava o acento no conhecimento humano. Para termos tecnologia, precisávamos daquilo que o Seabra costumava chamar de massa crítica, ou seja, de um grupo de profissionais capazes de fazer. No projeto que propus, destaquei a necessidade de capacitar professores, mas essa capacitação era diferente daquela que supostamente preparava docentes para usar computadores em seu ofício. A capacitação proposta por nós era a de que os docentes se tornassem autores de softwares educacionais. E, tornando-se autores, poderíamos dizer que produzíamos tecnologia na instituição. Essa ideia de autoria tinha limites. Não pretendíamos que os docentes se tornassem especialistas em programação. O que aprendiam de programação era apenas o suficiente para que produzissem um software "amador", que até poderia ser usado nos cursos de enfermagem, prótese ou ótica, mas que ainda carecia de muitas melhorias. A partir do que os docentes produziam, nossa equipe e colaboradores convidados davam um ar profissional ao produto, sempre dialogando com o professor-autor. E alguns dos softwares que produzimos alcançaram grande qualidade. O Fernando, o Luciano e o Seabra poderão falar sobre isso mais à frente. Posso dizer, com segurança, que fizemos um trabalho muito original, mas que ainda não foi reconhecido inteiramente por quem lida com computadores em educação.

\section{FAC - Você gostaria de acrescentar algo mais sobre o início do PIE?}

JNB - Nosso trabalho estava voltado para as necessidades do Senac, mas não nos isolamos. Em cada turma de capacitação (não mais do que dez professores), sempre reservávamos uma vaga para um professor convidado da rede pública de ensino. Além disso, desde o início nos articulamos com a equipe da Secretaria Estadual de Educação, que coordenava a introdução do uso de computadores no ensino das escolas públicas. E também fizemos algumas parcerias com pesquisadores que tinham propostas interessantes de produção de softwares. Um desses pesquisadores era o David Carraher, com quem produzimos Investigando textos como Sherlock e Divide and Conquer. Mas explicar essa observação vai esticar muito essa entrevista. Prefiro que os demais membros da equipe falem sobre nossa articulação com parceiros na área da Educação.

FAC - Em um momento que podemos caracterizar no Brasil como o da gestação da Idade Mídia, o PIE inovou bastante, inclusive, um tanto à frente de sua época. Cite algumas das inovações do programa que anteciparam tendências que vemos hoje no século XXI. 
JNB - O PIE praticava usabilidade bem antes que esse conceito se tornasse corrente no campo da informática. E o que é usabilidade? Usar computadores sempre exigiu a aprendizagem de alguns procedimentos que não faziam parte do repertório de saberes das pessoas. Na época em que nosso trabalho foi desenvolvido, a coisa era mais complicada do que hoje. Para usar um computador as pessoas precisavam dominar certos conceitos de como operar a máquina. Donald Norman, nome importante na comunidade das ciências da informação, explica isso com um caso muito claro do que ele chamou de "síndrome da tela negra". Isso ocorria quando alguém ignorava as demandas de como instruir a máquina ao estar diante de um computador ligado. A tela, inteiramente negra, mostrava uma luzinha a piscar. Para prosseguir era preciso que o usuário digitasse alguma instrução e pressionasse ENTER. Caso contrário, a tela continuaria negra, tendo como único sinal de vida um led ativado (aquela luzinha que piscava insistentemente). Isso impunha algumas barreiras ao uso de computadores. Enfrentamos o problema em duas frentes. $\mathrm{Na}$ primeira, criamos um software, o Introdução ao Micro, que ajudava as pessoas a se iniciarem em usos de computadores de maneira muito gentil (sem jargão informático, por meio de atividades lúdicas). Na segunda frente, produzimos softwares que eram exemplos de usabilidade. Professores e alunos que fossem utilizá-los não precisariam aprender o arcano discurso da informática. Vários membros da equipe poderiam falar mais sobre isso, usando principalmente o Introdução ao Micro como exemplo para mostrar que praticávamos usabilidade bem antes de esse conceito se tornar moeda corrente no campo da produção de softwares.

LR - O Jarbas citou um ponto importante. "Experiência do usuário" é um termo inventado no século XXI para abarcar de forma ampla temas como estudo de necessidades de usuário, design de interfaces, usabilidade e ergonomia em software. O termo é comumente abreviado como user experience (UX). O PIE tinha UX em seu "DNA". A manifestação mais constante disso era o cuidado com o design gráfico e de interação: cada pixel e cada teclada tinha que ter um motivo para existir, e esses motivos eram discutidos por todo o time interdisciplinar. Testes com usuários também faziam parte da nossa prática.

Um bom exemplo de UX além do design de interface era um detalhe do Introdução ao Micro, o software que criamos para apresentar aos alunos as partes básicas do computador, com foco no uso do teclado e convenções de interação na tela. Ele rodava no Apple $\|$ e, assim como muitos programas da época, era distribuído em um disquete gravado dos dois lados: uma parte do conteúdo ficava no lado A, outra parte, no lado B. O programa era feito para começar pelo lado A. Muitos programas na época eram assim, e, quando o usuário começava pelo lado $B$, aparecia na tela uma mensagem de erro que só um especialista era capaz de entender. Mas o Introdução ao Micro era diferente: se iniciado pelo lado $\mathrm{B}$, ele mostrava o menu principal de atividades e o usuário teclava um número para escolher uma delas. Se a atividade escolhida estivesse do lado A, o programa pedia para a pessoa retirar o disquete e colocá-lo do outro lado. Essa instrução era 
acompanhada de uma animação que mostrava o disquete sendo ejetado, virado e reinserido. Em vez de um erro, iniciar o programa pelo lado B se tornava uma atividade útil em si, não só para mostrar que o disquete tinha dois lados, mas também para aprender como manipulá-lo.

Essa característica do Introdução ao Micro foi fruto de observação de testes com usuários em seus primeiros contatos com microcomputadores em nosso laboratório no Senac Saúde. Tudo era novidade para eles, inclusive o disquete. E não era evidente que o disquete tinha dois lados, muito menos que cada lado poderia ter um conteúdo diferente. Explicando melhor: o leitor atento pode estar pensando que disquetes só entram no drive de um lado. Você está pensando emum disquete de 3.5 polegadas, aquele que aparece no ícone de "salvar" até hoje. Mas o padrão no Apple II era o disquete de 5.25", e o Apple II foi o primeiro computador capaz de ler e gravar os dois lados de um disquete, porém, apenas um lado de cada vez.

FMFJ - Antes falar de inovações do programa que anteciparam tendências que vemos hoje no século $\mathrm{XXI}$, quero agradecer o convite para a entrevista coletiva sobre o PIE, que foi mais uma grande iniciativa do Cordão que, como tantas outras, promove o encontro, a confraternização e o crescimento, sempre envolvendo gente querida e inteligente. Obrigado, Cordão!

Está claro que esse jeito de liderar é uma das chaves de sucesso do PIE, uma liderança positiva, humilde, extremamente respeitosa, que busca servir. A gestão do Cordão faz a engrenagem deslizar suave, quando em geral a liderança, como preferem chamar hoje em dia os experts no tema, costuma ser, em si, uma importante fonte de "calor" e "atrito". Sua liderança blindou o PIE da política pesada típica de uma organização grande e complexa como o Senac, garantiu as condições materiais e um espaço/tempo de sossego para o trabalho cotidiano sem interferências indevidas (que, no caso do PIE, seria um desastre!), promoveu o desenvolvimento de cada pessoa da sua equipe e o devido reconhecimento de cada um. Essa gestão foi ousada ao se comprometer com inovar na educação, um campo difícil e resistente, e soube defender e demonstrar as conquistas aos altos níveis estratégicos da organização. Não contava com experts no tema (com exceção do Jarbas) e não sobrevalorizava credenciais, experiências prévias e garantias daqueles que contratava. Satisfazia-se com inteligência, vivacidade, perspicácia, entrega. Nunca é demais lembrar que nenhum de nós tinha participado de um projeto de tecnologia educacional ou desenvolvido softwares ou pensado em processos de ensino e aprendizagem.

A novidade para nós era que a gestão do Cordão não pressionou por metas, KPIs [Key Performance Indicators ou Indicadores-chave de Desempenho], ROI [Return over Investment ou Retorno sobre o Investimento], P\&L [Profit and Loss Statement ou Demonstrativo de Lucros e Perdas], avaliações 360, sessões de feedbacks e tantas outras práticas prescritas hoje em dia na cartilha dos especialistas em gestão de pessoas. Poderia ser caracterizada, atualmente, na perspectiva da chamada 
gestão de talentos, como os atuais administradores e especialistas gostam de definir. Claro, todo esse ferramental tem sua importância, mas, em geral, "espana o parafuso" quando se trata de inovação e transformação digital, dois outros temas que estão em alta no mundo corporativo e com os quais esse resgate do PIE poderá colaborar. Em comum, essas ferramentas de gestão desenvolvidas pela e para a indústria são úteis para negócios conhecidos e de reprodução em escala. Por definição, emperram o que é desconhecido (inovador ou não), o que ainda não se repete ou não é repetível. Afınal, foram concebidas para isso, domesticar o risco!

o Cordão não estava sozinho nesse jeitão de liderar: embora com algumas diferenças, Jarbas seguia a mesma cartilha. Ele foi uma liderança-chave para o sucesso, pois liderou tecnicamente a equipe, definiu o norte, entregou referências, ensinou enquanto aprendeu. No dia a dia, construiu um ambiente horizontal no qual o saber e as opiniões de todos tinham espaço e valor, um ambiente no qual havia responsabilidades distribuídas, mas grande senso de cooperação e colaboração. Jarbas nunca usou um argumento de autoridade, sempre aglutinou pelo livre circular das ideias. Desse modo, todos nós desenvolvemos a confiança de pensar, de falar o que pensávamos, de arriscar sem medo. Esse ambiente aberto é, por excelência, o ambiente adequado para a aprendizagem e a inovação.

Jarbas foi a grande inspiração e fundação dos trabalhos do PIE. Sua presença mostra como é importante o conhecimento quando se quer inovar. Não um conhecimento enciclopédico, estático, mas um conhecimento vivo, dinâmico, repleto de perguntas muito mais do que respostas. Jarbas tinha predileção por pensar de modo disruptivo, inteligente, provocativo. Tinha um conjunto muito sólido de convicções bem fundamentadas quase inabalável (daí ser o alicerce), mas se divertia muito e, tenho certeza, tinha grande prazer, pelas risadas que ainda ouço, em desafiar seus conhecimentos junto com o grupo e seus fazeres. Aliás, por falar em risadas, como não lembrar do Cordão? A visão de gestão e de tecnologia do Jarbas pode ser sintetizada em uma passagem que ele gostava muito de contar, quando Al Rogers, um dos pioneiros de uso do computador na educação, teria dito ao diretor da escola em que lecionava para que desse a ele as chaves do laboratório de computadores, até então sempre trancado, ao que foi questionado sobre o que pretendia fazer, respondendo que não sabia. Como Rogers, talvez Jarbas não soubesse precisamente o que iria fazer, mas tudo o que foi feito pelo PIE estava ancorado em sua concepção de educação e tecnologia.

Cordão e Jarbas, os seniores da equipe com histórico no Senac, souberam construir um clima de aprendizado, de realizações e de grande envolvimento de todos nós. Isso não é nada fácil em qualquer grupo, mas era especialmente difícil em um grupo tão inquieto, tão despreparado para uma rotina acomodada. Essa forma de liderar criou as condições propícias para o desenvolvimento de uma equipe inteligente, perfeccionista, inovadora, produtiva e de alto desempenho. 
Esses são alguns dos aspectos de um dos temas, a gestão, que torna o relato sobre o PIE de interesse contemporâneo. Na mesma linha, incluiria temas como a concepção de tecnologia, de processos de ensino e de aprendizagem, da importância dos jogos e do desenvolvimento de software (não gosto do termo engenharia aplicada a esse caso, pois considero que não valoriza a dimensão artística implicada).

Sobre a concepção de tecnologia, certamente Jarbas poderá discorrer melhor e espero que o faça. Mas, para mim, na última linha fica a ideia de que tecnologia é um tipo específico de conhecimento prático-teórico (nessa ordem) que revela profundamente a relação humana (e de animais superiores) com o mundo social, emocional e cognitivo. Daí resulta que toda tecnologia está no mundo em relação direta com as necessidades e desejos em ação. Não há tecnologia parada. O PIE foi ação pura e isso é uma integridade de princípios. Tudo o que foi feito foi coerente com esse princípio, como, por exemplo, o desenvolvimento dos professores que passaram pelo PIE, que partia dos problemas diagnosticados em suas ações pedagógicas concretas e resultava em formas concretas de ação solucionadora por meio de softwares.

Sobre processos de ensino e aprendizagem, há vários aspectos a destacar, todos muito contemporâneos. Um dos principais é a valorização de um tipo específico de função do professor como sujeito capaz de refletir e propor experiências de aprendizagem intensas, profundas, que movam as entranhas do aluno por meio de curiosidade, deslocamentos, translações. O professor não é um mero reprodutor de esquemas alheios ou um repositório de conhecimentos especializados: é um autor de designs. Outro aspecto de destaque em relação às concepções de processos de ensino e aprendizagem é que a aprendizagem se dá melhor na ação do que na contemplação. Tudo é organizado de modo a criar as condições que promovam essa ação. É o que hoje em dia chamam de metodologias ativas ou aluno ativo, embora há tempos alguns educadores já tenham defendido conceitos similares, como Dewey, por exemplo.

Sobre os jogos, tenho uma intuição de que tanto as ideias de design de experiências pedagógicas trazidas pelo Jarbas quanto a ideia de desenvolvimento de software como design conversam com o design de jogos. O fato é que eu sempre me senti muito "em casa" tratando de temas de ensino e aprendizagem, tecnologia educacional e desenvolvimento de software, e intuo que essa familiaridade seja algum grau de transposição da experiência com jogos. Há algum tempo temos visto ganhar força o conceito de gamificação, ainda que por vezes seja proposto de forma pouco profunda. Não resta dúvida, contudo, que se disseminou por toda parte, pelas interfaces em geral.

Por fim, sobre o desenvolvimento de software: embora não codifique ou estude programação há um bom tempo (ainda volto lá!), nunca deixei de coordenar equipes de desenvolvimento e de conceber e arquitetar programas desde que saí do PIE. Então, posso assegurar que aquela era uma época áurea da computação, quando já se programava em alto nível e para equipamentos domésticos usados por gente comum, mas ainda se empurravam adiante as fronteiras da massificação do uso dos 
computadores. Muito do que fazíamos é hoje atualíssimo em termos de técnicas de desenvolvimento. O envolvimento do usuário (professor e aluno), de especialistas (enfermeiras, protéticos etc.), as interfaces gráficas para user interface (UI) e UX, a gamificação, a preocupação com a experiência, com a jornada do usuário, sem falar que tínhamos um rigor editorial incomum no desenvolvimento de software, textos bem escritos, instruções claras, ortografia correta, tipologia adequada.

CS - O Fernando falou em tecnologia, mas quero apresentar uma complementação da ideia por ele exposta, pois conceituar tecnologia é fundamental em uma área de ponta como a informática, na qual se cultuam tantos totens tecnológicos - em que se consideram obsoletos computadores que sequer tiveram suas possibilidades exploradas, e a "culpa" pelo não uso é sempre da falta de equipamentos melhores. Como contraponto ao conceito de tecnologia podemos mencionar o Kwait: um país que pode comprar os computadores mais potentes, os carros mais velozes, os videocassetes mais modernos, mas que não sabe construir ou sequer consertar qualquer um deles. O inverso disso é o personagem Robinson Crusoé, clássico de Daniel Defoe: de mãos nuas, escapando de um naufrágio, reproduz em sua ilha deserta toda a tecnologia da época usando apenas seu conhecimento e a vontade de transformar a realidade. Ou seja, não podemos confundir artefatos tecnológicos com tecnologia, a geradora deles. Na educação, essa distinção é fundamental, pois não há máquina que substitua o professor (e, quando isso ocorre, é porque o professor o merece). Tecnologia educacional é, por exemplo, usar uma lata de água, um pedaço de madeira e uma pedra para explicar a flutuação dos corpos; apertar a tecla de um vídeo sobre o assunto e deixar os alunos assistirem-no passivamente, em contrapartida, nada tem de tecnologia. Enfım, tecnologia é saber fazer.

Os objetivos iniciais do PIE eram a pesquisa de softwares já prontos e o desenvolvimento de metodologias de utilização nos cursos do Senac. O que hoje em dia é um grande problema, no século passado, era quase uma impossibilidade. Essa constatação levou-nos a partir para o desenvolvimento de software educacional - o que acabou se revelando um grande acerto, não apenas pelos programas em si, mas, principalmente, pelo desenvolvimento dos recursos humanos envolvidos e pela visão crítica dos objetivos e conteúdos dos cursos analisados. Nesse processo foram desenvolvidos mais de 20 softwares, inicialmente para a linha Apple, e depois para IBM-PC e Macintosh. O primeiro passo no processo de desenvolvimento desse tipo de material é a análise da área a "atacar". No Senac, optou-se pelos cursos da área da Saúde como início do trabalho - sendo dessa área a maioria dos programas até agora desenvolvidos. Em seguida, montaram-se equipes multidisciplinares para o estudo dos objetivos, levantamento das dificuldades de ensino mais recorrentes e prototipagem do software propriamente dito. O método de desenvolvimento de um software, educacional ou não, tem muito em comum com o processo de editoração de um livro: exige o envolvimento de profissionais de diversas áreas, desde especialistas no conteúdo específico até ilustradores e redatores, agregando-se, nesse caso, também vários tipos de profissionais da área de informática. Da interação desses 
conhecimentos específicos e do embate muitas vezes caloroso de ideias nasce o protótipo, que então deve ter muitas horas de testagem com alunos, com o devido acompanhamento especializado, para as modificações e validação definitiva (embora, nesse mundo, o termo "definitivo" pareça muito transitório, sempre originando novas versões). O custo envolvido nesse processo não é pequeno e o tempo investido é muito maior que o desejo de ver o software pronto. E isso se torna mais verdadeiro quando o produto em questão é uma simulação (para fazer programinhas de exercitação, tipo pergunta-e-resposta, gastam-se muitíssimo menos tempo e dinheiro em termos absolutos - mas quase nada se agrega de novo ao processo educacional). Grosso modo, podemos estimar que o custo do hardware corresponde a 10\% do investimento necessário, o software (é preciso software para desenvolver softwares) corresponde a algo como $20 \%$ e, finalmente, mas não por último, o chamado peopleware, absorvendo cerca de $70 \%$ dos custos: professores, técnicos, analistas, consultores, programadores de telas, ilustradores, redatores, editores, programadores de rotinas específicas (sonoras, linguagem de máquina, animações etc.) e programadores de alto nível, revisores, equipe de testagem etc.

RS - Muitos foram os ganhos e as contribuições do PIE que continuam presentes no século XXI, embora muitas vezes com nomes diferentes. Um exemplo que foi citado pelo Fernando merece ser explorado: as chamadas metodologias ativas. Na época do PIE, não usávamos essa terminologia, mas seus princípios nortearam muitos dos nossos produtos, em particular nas simulações. De uma forma bastante simples, podemos dizer que uma simulação, em informática, objetiva "imitar" processos ou operações do mundo real. É possível, em sala de aula, realizar simulações sem o uso do computador, mas as simulações no computador podem trazer mais realismos, mais variáveis e facilitar o trabalho do professor. Hoje, quando vejo alguns exemplos de simulações na prática das metodologias ativas, sempre fico com a sensação de que são estudos de caso, e não simulações propriamente ditas. Mas isso é conversa para outro momento.

No PIE, desenvolvemos algumas simulações e, em outros casos, usamos alguns softwares do Tom Snyder para trabalhar essa dinâmica em sala de aula. Até chegamos a iniciar um, nos moldes dos produtos do Snyder, que foi o Administração de Micro e Pequena Empresa. Penso que o Jarbas o esqueceu por ele não ter sido finalizado $100 \%$. Posteriormente, quando o PIE tinha deixado de existir, eu e mais um componente do grupo, o Paulo Candido, desenvolvemos, para o próprio Senac, três títulos com essa metodologia: Investigações em Ótica Geométrica e O Sangue são apenas dois dos exemplos de simulação que produzimos.

Além dos custos mencionados pelo Carlos, uma simulação precisa, mais do que nunca, do protagonismo do professor. Ele pode e deve ser o orientador, o condutor das discussões que contribuem para que os alunos levantem hipóteses, testem suas ideias, refutem algumas, validem outras, pensem sobre o que pensaram, enfim, construam conhecimentos. O professor não mais será aquele que tem as respostas corretas, mas o que estimula o pensar e facilita, no linguajar contemporâneo, o desenvolvimento de competências. 
Ao falar do trabalho com hipóteses, lembrei-me de um software concebido pelo Prof. Dr. David Carraher, parceiro em muitas jornadas, como o Jarbas já mencionou, e desenvolvido pelo PIE. Estou falando do Dividir para Conquistar (Divide and Conquer), que Jarbas e o próprio David chamam de software inteligente. Como o nome sugere, ele objetiva trabalhar com a operação matemática de divisão, porém não é um software de exercitação com respostas certas e erradas. O usuário deve descobrir os valores numéricos de algumas incógnitas e, para tal, tem que testar algumas hipóteses e se perguntar sobre sua validade. Ele pode ser usado por apenas uma pessoa ou em grupo. É no trabalho em grupo que destaco mais uma contribuição para o século XXI: a aprendizagem colaborativa.

Ao provocar o Jarbas sobre o produto Anotações de Enfermagem, tinha duas intenções: a primeira era lembrar que esse tema foi uma demanda dos professores de enfermagem, mas que, na época, os recursos da informática eram precários para o desenvolvimento de vídeos, daí a decisão de fazer em outra mídia. A informática do fim do século XX parecia um dinossauro perto do que estamos acostumados a ver e usar no século XXI. E, a segunda, era que esse trabalho mudava o conceito do que é ensinar a produzir uma comunicação escrita a partir de um evento. Não trabalhamos com roteiros de anotações de enfermagem. Criamos situações/eventos que poderiam gerar tais comunicações.

Para finalizar, mas com a sensação de que deixei muitos temas de lado, quero lembrar o importante papel que o PIE teve em disseminar e estimular a discussão sobre o uso da informática como recurso de ensino e aprendizagem. Realizamos diversas Jornadas de Informática e Educação, com a participação de nomes internacionais e nacionais que estavam envolvidos com essa temática - e não posso deixar de mencionar a memorável participação do Professor Paulo Freire em um desses eventos. As jornadas eram, preferencialmente, voltadas para professores de escolas públicas, mas também com a participação de instituições privadas. Nelas apresentávamos tanto reflexões teóricas como oficinas, que chamávamos de "mão na massa" e que atualmente podem ser denominadas de maker. Além dos eventos organizados pelo PIE, tivemos participações ativas em outras iniciativas, como as organizadas pela Fundação para o Desenvolvimento da Educação (FDE), e sucessos internacionais.

FAC - Para concluir, quero agradecer imensamente a participação de todos e lembrar que tivemos um software premiado pelo MEC - Dosagem de Insulina. Tivemos outro que ganhou um prêmio de excelência gráfica - Investigando textos com Sherlock, além de, sem qualquer modéstia, alguns softwares reconhecidos internacionalmente. Podemos falar sobre isso em uma próxima entrevista para o mesmo BTS - Boletim Técnico do Senac, a nossa Revista de Educação Profissional. 